\title{
The perspective on standardisation and harmonisation: the viewpoint of the EASI president
}

\author{
Jan Damoiseaux* (1)
}

\begin{abstract}
Standardisation of immuno-assays for autoantibodies is a major challenge. Although multiple organisations participate in the generation of internationally accepted standards, adequate standardisation of assays has not yet been achieved. Harmonisation may offer an alternative approach to better align requesting, testing, reporting and interpretation of autoimmune diagnostics. The European Autoimmunity Standardisation Initiative (EASI) was founded to facilitate both standardisation as well as harmonisation of autoantibody tests, but over the years the focus has drifted away from standardisation in favour of harmonisation. In the current paper the options for harmonisation are highlighted.
\end{abstract}

Keywords: Autoantibody, Harmonisation, Standardisation

\section{Introduction}

The European Autoimmunity Standardisation Initiative (EASI) was founded in 2006 to stimulate standardisation and harmonisation of autoantibody tests for optimal patient care [1]. Standardisation can be defined as the process of implementing a standard preparation in order to maximize compatibility of test results, eventually resulting in uniformity. Harmonisation, on the other hand, can be defined as the adjustment of differences and/or inconsistencies among different measurements, methods, and procedures to make them uniform or mutually compatible. Harmonisation is typically achieved by agreement as consolidated in recommendations and/or guidelines. Although standardisation has been achieved for multiple laboratory parameters in clinical chemistry and hematology, standardisation of autoantibody assays has appeared a major challenge. Considering that the measurand, i.e., antibodies, consists of a highly variable mixture of molecules that are different in terms

*Correspondence: jan.damoiseaux@mumc.nl

Central Diagnostic Laboratory, Maastricht University Medical Center, P.

Debyelaan 25, 6229 HX Maastricht, The Netherlands of epitope recognition, degree and type of glycosylation, isotype and subclass distribution, and avidity, the awareness has increased that standardisation of autoantibody assays might be an utopia. This is elegantly illustrated in the example of anti-dsDNA antibodies [2]. In the current paper, as president of the EASI Forum Group, I will highlight my personal view on the challenges of autoantibody standardisation and the options of harmonisation in autoimmune diagnostics.

\section{Standardisation}

In the past, several internationally accepted standard preparations for autoantibody detection have been launched by a multitude of distinct organisations [3]. For instance, the World Health Organisation (WHO) prepared standards for rheumatoid factor (RF; W1066 assigned 25 international units (IU)), and anti-dsDNA antibodies (W0/80 assigned $200 \mathrm{IU}[4,5]$. The W1066 standard, originally referred to as $64 / 1$, was prepared by the Dutch Bloodbank (Sanquin, Amsterdam) as a serumpool of 197 patients with rheumatoid arthritis (RA). The W0/80 standard, on the other hand, was plasmapheresis material of a single patient with systemic lupus

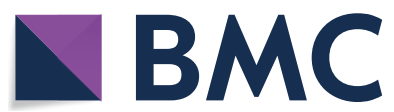

(c) The Author(s) 2020. This article is licensed under a Creative Commons Attribution 4.0 International License, which permits use, sharing, adaptation, distribution and reproduction in any medium or format, as long as you give appropriate credit to the original author(s) and the source, provide a link to the Creative Commons licence, and indicate if changes were made. The images or other third party material in this article are included in the article's Creative Commons licence, unless indicated otherwise in a credit line to the material. If material is not included in the article's Creative Commons licence and your intended use is not permitted by statutory regulation or exceeds the permitted use, you will need to obtain permission directly from the copyright holder. To view a copy of this licence, visit http://creativeco mmons.org/licenses/by/4.0/. 
erythematosus (SLE). Also the Autoantibody Standardizing Committee (ASC), a subcommittee of the International Union of Immunological Societies (IUIS) quality assessment and standardization committee has generated a broad panel of reference materials for autoantibody detection, including standards for myeloperoxidase (MPO) anti-neutrophil cytoplasmic antibodies (ANCA) and proteinase 3 (PR3)-ANCA [6]. Both standards were each prepared from plasmapheresis material of single patients with ANCA-associated vasculitis (AAV) and were assigned a value of $100 \mathrm{IU}$. Although the assignment of IU is a privilege of the WHO, it should be acknowledged that the ASC operates on behalf of the WHO. More recently, standards for MPO-ANCA (ERM-DA476/ IFCC) and PR3-ANCA (ERM-DA483/IFCC) were also prepared by the Institute for Reference Materials and Methods (IRMM), in collaboration with the Working Group Harmonisation of Autoantibody Tests (WG-HAT) of the International Federation of Clinical Chemistry and Laboratory Medicine (IFCC) [7, 8]. Also these standards were prepared from plasmapheresis material of single patients with AAV and are assigned a value in mass units. The advantage of the IRMM standards has been claimed to be the commutability, i.e., the equivalence of the mathematical relationships between the results of different measurement procedures for a reference material and for representative samples from healthy and diseased individuals.

The main question about the currently available standards for autoantibody diagnostics is what these standards have brought us until today. Evidently, this is not the intended standardisation of test results. In case of AAV the ASC MPO- and PR3-ANCA standards have been used by several diagnostic companies, but this has not resulted in alignment of results [9]. Whether the claimed commutability of the IRMM ANCA standards will solve the problem, remains to be established. The fact that the ASC and IRMM ANCA standards reveal quite similar results within the same immunoassay, but clearly differ from one assay to the other, does not hold great promise for the new standards (Bossuyt et al., manuscript in preparation). The WHO standard for anti-dsDNA antibodies has uncovered another important caveat of standards that have been prepared from a single patient. The stock of the WHO standard has run out and, next, it appeared impossible to replace by a novel standard with the same characteristics. The novel material (15/174), therefore, is not released as a new WHO standard, but only as reference material [10]. Consequently, the reference material has been assigned a nominal value of 100 U/ampoule and, as such, is not defined in IU. Obviously, the problem of not being able to replace a standard preparation, could potentially be solved by making a large pool of serum obtained from multiple patients. Considering the complexity of the idiotype - anti-idiotype network it can be imagined that the autoantibody reactivity changes considerably after pooling the sera. To circumvent this problem, a novel megapool strategy has been applied in the establishment of an international autoantibody reference standard for human anti-DFS70 antibodies [11]. This strategy is based on stepwise pooling of sera and consistently checking for antibody reactivity in several distinct methods after each step of pooling. This reference standard is now integrated in the panel of ASC standards. Although this material is referred to as 'standard', the intentional use is for proper assay validation and interpretation of the dense fine speckled HEp-2 indirect immunofluorescent assay (IIFA) pattern (AC-2), i.e., not for standardisation of distinct immunoassays enabling detection of anti-DFS70 antibodies. Nevertheless, it is to be expected that pooling of sera will create a mixture with a broad spectrum of epitopes recognized, glycosylation, and avidities, in combination with an average distribution of isotypes and subclasses. The megapool approach can be compared with the production of intravenous immunoglobulin preparations. By starting with a huge number of donors a wide spectrum of potential antibody variants will be included and lot-to-lot variation will be minimized. As shown for RF by Jacobs and Bossuyt, such pools become more commutable, resulting in similar results for the pool of sera in different immunoassays [12]. However, even standards based on pooled sera, such as the W1066 RF standard, may give aberrant results in distinct immunoassays that have been calibrated on this standard and express the results in IU [13]. Similar conclusions were derived from a Dutch study using an alternative pool of RF sera as reference [14], the so-called Reference Laboratory for Rheumatologic Serology (RELARES) with a defined IgM-RF level of $200 \mathrm{IU} /$ $\mathrm{mL}$ [15]. Not surprisingly, individual sera still revealed quite different results in these immunoassays (Fig. 1 and [12]). Apparently, the source of the autoantigen and the way the autoantigen is presented in the immunoassay are critical parameters for taking into account if standardisation is to be achieved.

\section{Harmonisation}

Because of the difficulties encountered in the process of standardisation, EASI has shifted the focus from standardisation toward harmonisation. As precipitated in the definition of harmonisation, this is to be achieved by recommendations and guidelines. This can happen at multiple levels (Fig. 2) and typically requires optimal bidirectional communication between the clinician and the laboratory specialist [16]. 


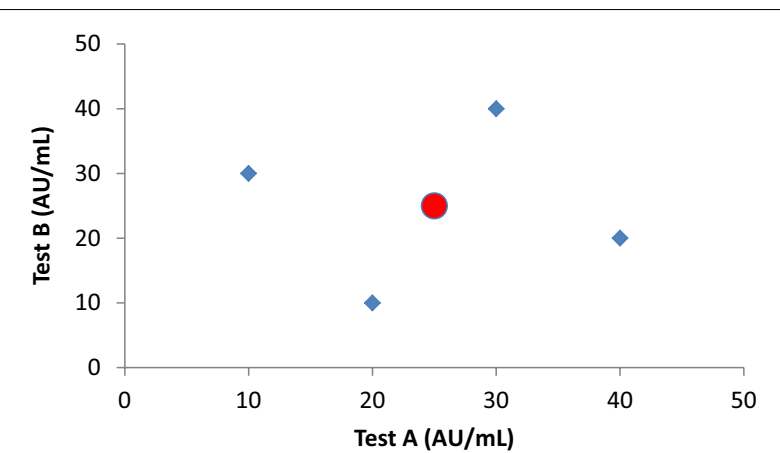

Fig. 1 The effect of pool-sera in relation to individual test results. If equal amounts of 4 samples with different reactivities $(10,20,30$ and $40 \mathrm{AU} / \mathrm{mL}$; blue diamonds) in 2 immuno-assays are mixed, the pool-serum probably will reveal the average reactivity $(25 \mathrm{AU} / \mathrm{mL}$; red circle) in both assays. If both assays would be calibrated on this pool-serum, the individual test results of the 4 samples will remain different. This obviously also holds for megapools

The first level of harmonisation involves the definition of clinical manifestations that warrant the request for a certain autoantibody test. Due to automation of autoantibody serology many assays, nowadays, are widely available, even outside laboratories specialised in autoimmune diagnostics. This has enormously increased the number of requests and diversified the clinical disciplines requesting such assays at the cost of a valid pre-test probability as defined by the clinical manifestations of the patient. This is best exemplified by the situation for antinuclear antibodies (ANA), eventually resulting in positive results that are not easily explained by the clinical manifestations being apparent at the time of presentation [17]. In case of AAV, the first international consensus on ANCA testing clearly defined the clinical manifestations that justify the request for an ANCA test [18]. This gating strategy has been proven to be effective in several studies [19-21], and therefore was reinforced in the 2017 international consensus on ANCA testing [22]. Obviously, in most diagnostic and/or classification criteria the defined clinical criteria implicitly include the clinical manifestations that call for autoantibody diagnostics [23-25].

Based on the clinical manifestations, to be communicated by the clinician to the laboratory specialist, the optimal testing conditions can be applied in the laboratory. In particular for the systemic autoimmune diseases the autoantibody testing is precipitated in an algorithm. For the ANA-associated rheumatic diseases (AARD), the HEp-2 IIFA has been advocated as the most optimal screening test [26, 27], but this is currently being

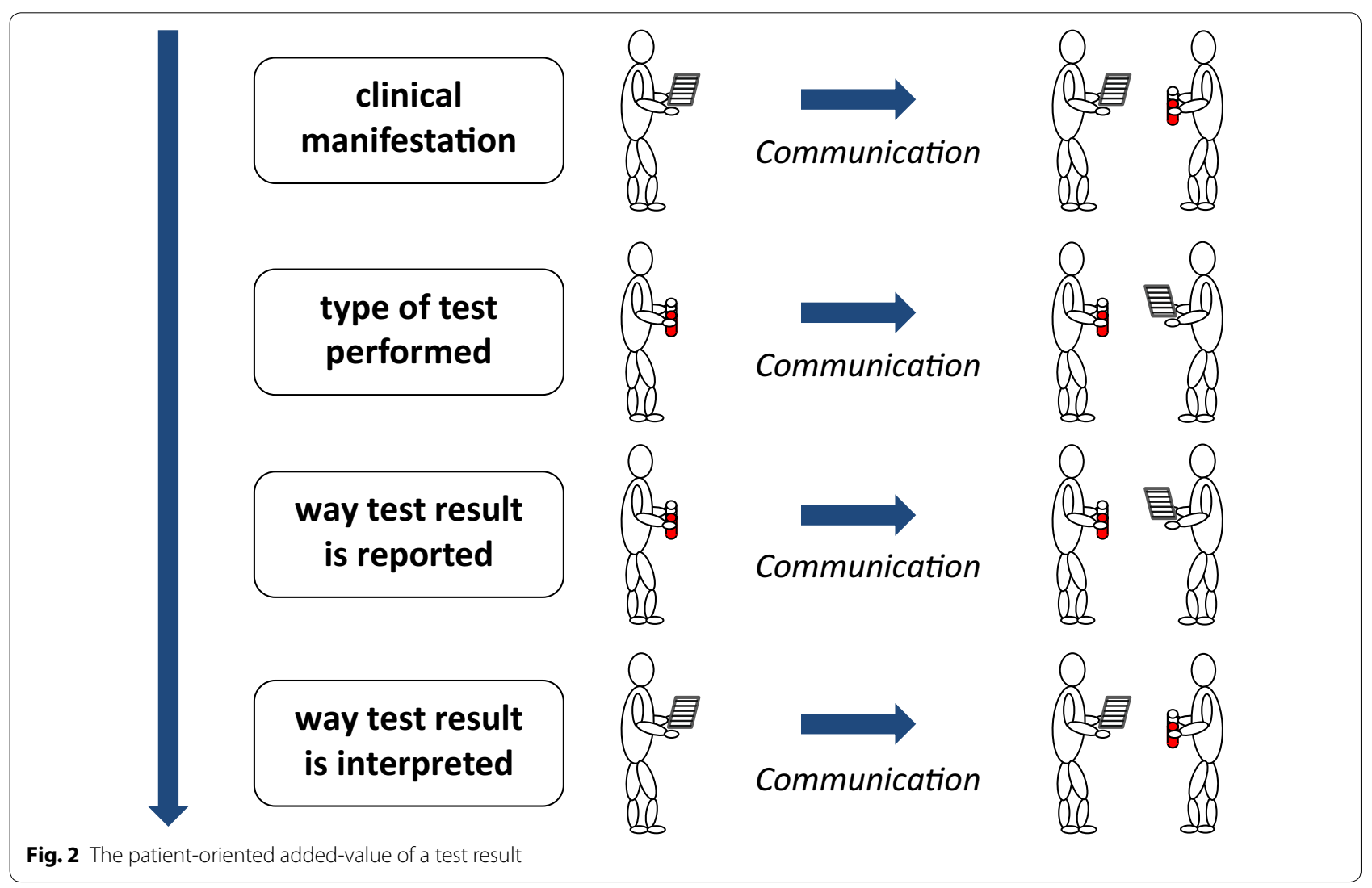


challenged because this might be different for the distinct AARD entities [28, 29]. In case of the idiopathic inflammatory myopathies (IIM), screening with HEp-2 IIFA may not be the best choice, although the currently available multiplex immunoassays for IIM-specific autoantibodies also harbour some challenges [30, 31]. Importantly, reference to assay specification, or the lack thereof, in classification criteria for these diseases also may impact the testing algorithm. For instance, the classification criteria for systemic sclerosis (SSc) include anti-centromere antibodies in the domain of relevant autoantibodies [24]. For these anti-centromere antibodies it is sufficient to identify the centromere pattern in the HEp-2 IIFA. The new ACR/EULAR criteria for SLE allow the use of alternative immunoassays instead of the HEp-2 IIFA if such an assay at least has an equivalent performance [25]. Since ANA are taken as an entry criterium, this equivalent performance should primarily be based on high sensitivity, but, unfortunately, the definition of equivalent performance is not provided. Whatever the choice of screening test, a positive test is intended to be followed by antigen-specific immunoassays in order to identify autoantibodies more specific for a certain disease type. In general, these follow-up tests for AARD enable detection of about 6-10 distinct autoantibodies. The availability of clinical information, as far as appropriate, will enable to select for disease-specific profiles as available for IIM and SSc. Since in several countries automatic reflex testing is not allowed, the laboratory specialist at least can advise the clinician to request for analysis of the most relevant autoantibodies. While the discussion on the most optimal screening test for AARD is still on-going, for AAV it has been shown in a recent multicenter study that screening with antigen-specific immunoassays, i.e., detection of MPO- and PR3-ANCA, is to be preferred above screening by IIFA on ethanol-fixed neutrophils [32], and this finding has resulted in revision of the international consensus on ANCA testing for AAV [22]. The latter is a clear example of harmonisation by an evidence-based consensus on the testing algorithm for an autoimmune disease.

Next, the test-results have to be reported to the clinician, preferentially in a universal manner. It is important that the results are reported in the context of reference values and with information about the methods used. For quantitative assays, in general, two cut-offs are provided that indicate a grey-zone. The highest cut-off is considered the upper limit of normal and this is often referred to in the context of diagnostic and classification criteria, for instance for coeliac disease and RA $[23,33]$. Unfortunately, there is substantial difference in the way diagnostic companies define the cut-off of their immuno-assays and this contributes to differences in test characteristics [13, 32]. Harmonization in reporting of test-results could be achieved if results were to be reported in likelihood ratio's (LR) and, in particular, in LR for test-result intervals [34]. Obviously, also for calculating a single LR or multiple LR for test-result intervals, the cut-off or multiple cut-offs, respectively, are important. This approach has proven to be very effective for distinct ANCA immuno-assays [35]. One step further is to report LR for each quantitative result instead of arbitrary units [36]. An important caveat of reporting in LR might be that LR for the same immuno-assays may be different for distinct geographical areas due to, for instance, variation in ethnicity or infectious burden. World-wide multi-center studies of sufficient magnitude have to be performed in order to validate to what extent LR can be generalized. Another challenge is the universal use of terminology and definitions. In particular in diagnostic and classification criteria for autoimmune diseases the terminology in relation to autoantibodies is poorly defined. In the recent classification criteria for SLE it is not clear if ANA include only antibodies to nuclear antigens, or also to cytoplasmic antigens [25]. There is no consensus on this issue between different countries [37], but this evidently has impact on the test-characteristics. Similarly, the original classification criteria for Sjögren's syndrome include autoantibodies to SSA, but there is no differentiation between autoantibodies to SS-A/Ro60 and Ro52/TRIM21 [38]. In a later publication about the clinical practice of the Sjögren's syndrome, it is stated that only anti-SS-A/Ro60 antibodies have to be considered, because isolated anti-Ro52/TRIM21 antibodies are not specific for the Sjögren's syndrome [39]. Although this latter conclusion is in line with daily life experience, the original publication could not differentiate between both autoantibodies because in the patient cohorts used to define and validate the criteria this distinction was not made [38]. The lack of clear-cut definitions for terminology used in autoimmune diagnostics is also reflected in routine clinical practice and this may result in misinterpretation of test-results by the clinician. In particular in the field of the HEp-2 IIFA, the International Consensus on ANA Patterns (ICAP) has made important advances in harmonizing the terminology [40]. ICAP has reached consensus on the name and definition of multiple HEp-2 IIFA patterns. Moreover, since the ICAP information has been translated in multiple languages, implementation of ICAP is strongly facilitated.

Finally, the clinician has to interpret the reported test result in the context of the clinical manifestations of the patients. Evidently, reporting in LR would facilitate correct test-result interpretation, especially if the relation between pre- and post-test probability is graphically presented as a function of the LR [34]. Such graphics could 
Table 1 Definitions and requirements for standardisation and harmonisation

\begin{tabular}{|c|c|c|}
\hline & Standardisation & Harmonisation \\
\hline Definition & $\begin{array}{l}\text { Implementation of a standard preparation in order to maximize } \\
\text { compatibility of test results, eventually resulting in uniformity }\end{array}$ & $\begin{array}{l}\text { Adjustment of differences and/or inconsistencies among different } \\
\text { measurements, methods and procedures to make them uniform } \\
\text { or mutually compatible }\end{array}$ \\
\hline \multirow[t]{4}{*}{ Requirements } & $\begin{array}{l}\text { Establishment of an internationally accepted measuring unit as } \\
\text { defined by a standard preparation }\end{array}$ & $\begin{array}{l}\text { Consensus on clinical manifestations that warrant the request of } \\
\text { the test; to be defined in guidelines }\end{array}$ \\
\hline & $\begin{array}{l}\text { Application of the measuring unit in a wide variety of immuno- } \\
\text { assays }\end{array}$ & $\begin{array}{l}\text { Consensus on testing algorithms to be used for distinct autoim- } \\
\text { mune diseases; to be defined in guidelines }\end{array}$ \\
\hline & $\begin{array}{l}\text { Implementation of the standardised measuring unit reveals } \\
\text { identical test results in individual samples, independent of the } \\
\text { immuno-assay of choice }\end{array}$ & $\begin{array}{l}\text { Consensus on reporting of autoantibody results in combination } \\
\text { with test characteristics; to be defined in guidelines }\end{array}$ \\
\hline & $\begin{array}{l}\text { Well-defined composition of the standard preparation in order to } \\
\text { guarantee replacement by identical standard preparation }\end{array}$ & $\begin{array}{l}\text { Optimal communication between laboratory specialist and clini- } \\
\text { cian for adequate interpretation of test results }\end{array}$ \\
\hline
\end{tabular}

also give insight in the way test-results for autoantibodies are integrated in diagnostic and classification criteria. While in the classification criteria for RA both IgM RF and ACPA have been assigned the same value, it is evident that high-level IgM RF have a similar performance as low-level ACPA as defined by the relation between pre- and post-test probability presented as a function of the LR [41]. The challenge for the clinician is to make a good estimation of the pre-test probability based on the (combination of) clinical manifestations. For this, it would be helpful to define the pre-test probability of the clinical manifestations that warrant the request of the test. Although the concept of LR seems to be restricted to quantitative immuno-assays, it is also applicable for HEp-2 IIFA as far as fluorescence intensity values are provided [42]. Alternatively, ICAP has defined the clinical relevance of distinct HEp-2 IIFA patterns in order to support the clinician in requesting adequate follow-up tests in the context of the differential diagnosis [43]. Also for this step in the diagnostic work-up of the patient it is relevant that there is communication between the clinician and the laboratory specialist. Knowing the final diagnosis enables the laboratory specialist to monitor test performance of the respective immuno-assay.

\section{Conclusions}

For standardisation in autoimmune diagnostics to become a reality, multiple hurdles have to be taken (Table 1). Current approaches evidently have not resulted in achieving the goal of standardisation. One of the problems with standards derived from patient material is the limited availability and poor reproducibility after replacement. Restrictions in the variation of distinct aspects of the immunoassays, like the source of the autoantigen, might further help to achieve standardisation, but this is, obviously, hampering the introduction of innovations in autoantibody detection. Altogether, standardisation in autoimmune diagnostics seems to be an utopia.

Harmonisation, on the other hand, might be more feasible since this can be achieved by reaching a consensus on defining which clinical manifestations warrant the request of a specific autoantibody test, on the optimal testing algorithm for a specific autoimmune disease, on the way test-results are to be reported to the clinician, and the way these test-results are interpreted in the clinical context of the patient (Table 1). Bidirectional communication between clinician and laboratory specialist is an essential element in this process of harmonisation and this requires clear-cut definitions of the terminology used. Evidently, also for harmonisation there are multiple challenges. Besides lacking data, i.e., potential geographical differences in LR or pre-test probabilities of defined clinical manifestations, reaching consensus on the items mentioned requires close collaboration between the clinical parties involved in autoimmune diagnostics. These parties should also include organisations like the ACR and EULAR that are involved in defining diagnostic and classification criteria, as well as the diagnostic industry. Better defining, and possibly renaming, of terminology is an item that could be initiated by EASI. As for other terms, it will not be easy if EAS(tandardisation)I has to change its name in EAH(armonisation)I.

\section{Acknowledgements}

All EASI-members of the EASI Forum and the national EASI-teams are acknowledged for their active participation in the discussions that have resulted in the current manuscript.

\section{Authors' contribution}

As single author JD is responsible for the conception and writing of the manuscript. The author read and approved the final manuscript.

\section{Funding}

Not applicable.

Availability of data and materials

Not applicable. 
Ethics approval and consent to participate

Not applicable.

\section{Consent for publication}

Not applicable.

\section{Competing interests}

EASI is supported by Thermo Fisher Diagnostics; TFD does not have any influence on the content discussed at EASI, but acts purely as a facilitator.

Received: 2 December 2019 Accepted: 21 January 2020

Published online: 06 February 2020

\section{References}

1. Damoiseaux J, Olschowka N, Shoenfeld Y. EASI_European autoimmunity standardisation initiative: facing the challenges of diagnostics in autoimmunity. Clin Chem Lab Med. 2018;56:1620-3.

2. Mummert E, Fritzler MJ, Sjöwall C, Bentow C, Mahler M. The clinical utility of anti-double-stranded DNA antibodies and the challenges of their determination. J Immunol Methods. 2018:459:11-9.

3. Damoiseaux J, Andrade LE, Fritzler MJ, Shoenfeld Y. Autoantibodies 2015: from diagnostic biomarkers toward prediction, prognosis and prevention. Autoimmun Rev. 2015;14:555-63.

4. Anderson SG, Bentzon MW, Houba V, Krag P. International reference preparation of rheumatoid arthritis serum. Bull World Health Org. 1970:42:311-8.

5. Feltkamp TE, Kirkwood TB, Maini RN, Aarden LA. The first international standard for antibodies to double stranded DNA. Ann Rheum Dis. 1988:47:740-6.

6. Chan EK, Fritzler MJ, Wiik A, Andrade LE, Reeves WH, Tincani A, et al. Autoantibody standardization committee in 2006. Autoimmun Rev. 2007;6:577-80.

7. Monogioudi E, Hutu DP, Martos G, Sheldon J, Schimmel H, Meroni PL et al. Development of a certified reference material for myeloperoxidase-anti-neutrophil cytoplasmic autoantibodies (MPO-ANCA). Clin Chim Acta. 2017;467:48-50.

8. Monogioudi E, Sheldon J, Meroni PL, Hutu DP, Schimmel H, Zegers I; Committee for the Harmonisation of Autoimmune Testing (C-HAT) of the International Federation of Clinical Chemistry and Laboratory Medicine (IFCC). (2019) Certified reference material against PR3 ANCA IgG autoantibodies. From development to certification. Clin Chem Lab Med. 57:1197-206.

9. Rasmussen N, Damoiseaux J, Csernok E, Heegaard NHH, Hellmich B, van Paassen $\mathrm{P}$, et al. Individual values of antineutrophil cytoplasmic antibodies do not correspond between antigen-specific assays. Clin Chem Lab Med. 2018;56:e39-42

10. Fox BJ, Hockley J, Rigsby P, Dolman C, Meroni PL, Rönnelid J. A WHO reference reagent for lupus (anti-dsDNA) antibodies: international collaborative study to evaluate a candidate preparation. Ann Rheum Dis. 2019. https://doi.org/10.1136/annrheumdis-2019-215845.

11. Dellavance A, Baldo DC, Zheng B, Mora RA, Fritzler MJ, Hiepe F, et al. Establishment of an international autoantibody reference standard for human anti-DFS70 antibodies: proof-of-concept study for a novel megapool strategy by pooling individual specific sera. Clin Chem Lab Med. 2019:57:1754-63.

12. Jacobs JFM, Bossuyt X. Standardization and harmonization of autoimmune diagnostics. Clin Chem Lab Med. 2018;56:1563-7.

13. Van Hoovels L, Jacobs J, Vander Cruyssen B, Van den Bremt S, Verschueren $P$, Bossuyt $X$. Performance characteristics of rheumatoid factor and anti-cyclid citrullinated peptide antibody assays may impact ACR/EULAR classification of rheumatoid arthritis. Ann Rheum Dis. 2018;77:667-77.

14. Falkenburg WJJ, von Richthofen HJ, Koers J, Weykamp C, Schreurs MWJ, Bakker-Jonges LE, et al. Clinically relevant discrepancies between different rheumatoid factor assays. Clin Chem Lab Med. 2018;56:1749-58.

15. Klein F, Janssens MB. Standardisation of serological tests for rheumatoid factor measurement. Ann Rheum Dis. 1987;46:674-80.

16. Tozzoli R, Bizzaro N. The clinical autoimmunologist and the laboratory autoimmunologist: the two sides of the coin. Autoimmun Rev. 2012;11:766-70.
17. Mahler M, Meroni PL, Bossuyt X, Fritzler MJ. Current concepts and future directions for the assessment of autoantibodies to cellular antigens referred to as anti-nuclear antibodies. J Immunol Res. 2014;2014:315179.

18. Savige J, Gillis D, Benson E, Davies D, Esnault V, Falk RJ, et al. International consensus statement on testing and reporting of antineutrophil cytoplasmic antibodies (ANCA). Am J Clin Pathol. 1999;111:507-13.

19. Mandl LA, Solomon DH, Smith EL, Lew RA, Katz JN, Shmerling RH. Using antineutrophil cytoplasmic antibody testing to diagnose vasculitis: can test-ordering guidelines improve diagnostic accuracy? Arch Intern Med. 2002;162:1509-14.

20. Sinclair D, Saas M, Stevens JM. The effect of a symptom related "gating policy" on ANCA requests in routine clinical practice. J Clin Pathol. 2004;57:131-4.

21. Arnold DF, Timms A, Luqmani R, Misbah SA. Does a gating policy for ANCA overlook patients with ANCA associated vasculitis? an audit of 263 patients. J Clin Pathol. 2010;63:678-80.

22. Bossuyt X, Cohen Tervaert JW, Arimura Y, Blockmans D, Flores-Suárez LF, Guillevin L, et al. Position paper: revised 2017 international consensus on testing of ANCAs in granulomatosis with polyangiitis and microscopic polyangiitis. Nat Rev Rheumatol. 2017;13:683-92.

23. Aletaha D, Neogi T, Silman AJ, Funovits J, Felson DT, Bingham CO III, et al. Rheumatoid arthritis classification criteria: an American college of rheumatology/European league against rheumatism collaborative initiative. Ann Rheum Dis. 2010;69:1580-8.

24. van den Hoogen F, Khanna D, Fransen J, Johnson SR, Baron M, Tyndall A, et al. 2013 classification criteria for systemic sclerosis: an American College of Rheumatology/European League against Rheumatism collaborative initiative. Arthritis Rheum. 2013;65:2737-47.

25. Aringer M, Costenbader K, Daikh D, Brinks R, Mosca M, Ramsey-Goldman $R$, et al. European League Against Rheumatism/American College of Rheumatology classification criteria for systemic lupus erythematosus. Ann Rheum Dis. 2019;78:1151-9.

26. Meroni PL, Schur PH. ANA screening: an old test with new recommendations. Ann Rheum Dis. 2010;69:1420-2.

27. Agmon-Levin N, Damoiseaux J, Kallenberg C, Sack U, Witte T, Herold M, et al. International recommendations for the assessment of autoantibodies to cellular antigens referred to as anti-nuclear antibodies. Ann Rheum Dis. 2014;73:17-23.

28. Meroni PL, Chan EK, Damoiseaux J, Andrade LEC, Bossuyt X, Conrad K, et al. Unending story of the indirect immunofluorescence assay on HEp-2 cells: old problems and new solutions? Ann Rheum Dis. 2019;78:e46.

29. Orme ME, Andalucia C, Sjölander S, Bossuyt X. A comparison of a fluorescence enzyme immunoassay versus indirect immunofluorescence for initial screening of connective tissue diseases: systematic literature review and meta-analysis of diagnostic test accuracy studies. Best Pract Res Clin Rheumatol. 2019:32:521-34

30. Damoiseaux J, Vulsteke JB, Tseng CW, Platteel ACM, Piette Y, Shovman $\mathrm{O}$, et al. Autoantibodies in idiopathic inflammatory myopathies: clinical associations and laboratory evaluation by mono- and multispecific immunoassays. Autoimmun Rev. 2019;18:293-305.

31. Platteel ACM, Wevers BA, Lim J, Bakker JA, Bontkes HJ, Curvers J, et al. Frequencies and clinical associations of myositis-related antibodies in The Netherlands: a one-year survey of all Dutch patients. J Transl Autoimmun. 2019. https://doi.org/10.1016/j.jtauto.2019.100013.

32. Damoiseaux J, Csernok E, Rasmussen N, Moosig F, van Paassen P, Baslund $B$, et al. Detection of antineutrophil cytoplasmic antibodies (ANCAs): a multicentre European Vasculitis Study Group (EUVAS) evaluation of the value of indirect immunofluorescence (IIF) versus antigen-specific immunoassays. Ann Rheum Dis. 2017;76:647-53.

33. Husby S, Koletzko S, Korponay-Szabó IR, Mearin ML, Phillips A, Shamir R, et al. European Society for Pediatric Gastroenterology, Hepatology, and Nutrition guidelines for the diagnosis of coeliac disease. J Pediatr Gastroenterol Nutr. 2012;54:136-60.

34. Bossuyt X. Clinical performance characteristics of a laboratory test. A practical approach in the autoimmune laboratory. Autoimmun Rev. 2009:8:543-8

35. Bossuyt $X$, Rasmussen N, van Paassen P, Hellmich B, Baslund B, Vermeersch $P$, et al. A multicentre study to improve clinical interpretation of proteinase-3 and myeloperoxidase anti-neutrophil cytoplasmic antibodies. Rheumatology. 2017;56:1533-41. 
36. Fierz W. Likelihood ratios of quantitative laboratory results in medical diagnosis: the application of Bézier curves in ROC analysis. PLoS ONE. 2018;13:e0192420.

37. Damoiseaux J, von Mühlen CA, Garcia-De La Torre I, Carballo OG, de Melo Cruvinel W, Francescantonio PL, et al. International consensus on ANA patterns (ICAP): the bumpy road towards a consensus on reporting ANA results. Auto Immun Highlights. 2016;7:1.

38. Shiboski SC, Shiboski CH, Criswell L, Baer A, Challacombe S, Lanfranchi $\mathrm{H}$, et al. American College of Rheumatology classification criteria for Sjögren's syndrome: a data-driven, expert consensus approach in the Sjögren's International Collaborative Clinical Alliance cohort. Arthritis Care Res. 2012;64:475-87.

39. Mariette $X$, Criswell LA. Primary Sjögren's syndrome. N Engl J Med. 2018;378:931-9.

40. Chan EK, Damoiseaux J, Carballo OG, Conrad K, de Melo Cruvinel W, Francescantonio $\mathrm{PL}$, et al. Report of the first international consensus on standardized nomenclature of antinuclear antibody HEp-2 cell patterns 2014-2015. Front Immunol. 2015;6:412.
41. Bossuyt X, Coenen D, Fieuws S, Verschueren P, Westhovens R, Blanckaert $\mathrm{N}$. Likelihood ratios as a function of antibody concentration for anti-cyclic citrullinated peptide antibodies and rheumatoid factor. Ann Rheum Dis. 2009;68:287-9.

42. Bossuyt X, Claessens J, Belmondo T, De Langhe E, Westhovens R, Poesen K. Harmonization of clinical interpretation of antinuclear antibody test results by solid phase assay and by indirect immunofluorescence through likelihood ratios. Autoimmun Rev. 2019. https://doi. org/10.1016/j.autrev.2019.102386.

43. Damoiseaux J, Andrade LEC, Carballo OG, Conrad K, Francescantonio PLC, Fritzler MJ, et al. Clinical relevance of HEp-2 indirect immunofluorescent patterns: the International Consensus on ANA patterns (ICAP) perspective. Ann Rheum Dis. 2019;78:879-89.

\section{Publisher's Note}

Springer Nature remains neutral with regard to jurisdictional claims in published maps and institutional affiliations.
Ready to submit your research? Choose BMC and benefit from:

- fast, convenient online submission

- thorough peer review by experienced researchers in your field

- rapid publication on acceptance

- support for research data, including large and complex data types

- gold Open Access which fosters wider collaboration and increased citations

- maximum visibility for your research: over $100 \mathrm{M}$ website views per year

At BMC, research is always in progress.

Learn more biomedcentral.com/submissions 